\title{
Gender, family, and community attachment in a new destination
}

\begin{abstract}
As new immigrant destinations in the U.S. have become home to more settled immigrant populations, they are also becoming less male-dominated and attracting more women and families. But this process is occurring unevenly, with some new destinations much more attractive to women than others. The factors that might lead a destination to attract or retain women are not well understood. We draw on interviews with long-time Latin American residents in a non-metropolitan community in Utah with a fairly high proportion of women immigrants to analyze the ways in which gender and other factors relate to community attachment in this specific context. We examine gender differences in satisfaction with the community, experiences of discrimination, and plans to remain in the community. Surprisingly, given current antiimmigrant trends in national politics, we found high levels of community attachment among both men and women. Although experiences of racism were common in our sample, many of the respondents were quick to downplay these experiences and focused instead on their overall positive assessment of the community. Women were more attuned to the experience of discrimination and less willing to downplay it. They were also less likely to have a long-term plan to remain in the community, but this appeared to be more related to their consideration of other family members' long-term plans, rather than due to their experiences of discrimination. These findings have implications for understanding gendered settlement patterns as well as for promoting immigrant integration at the local level in an unfavorable political context.
\end{abstract}

\section{Introduction}

Immigrants residing in cities and towns without a well-established immigrant population face many challenges in navigating daily life in their new communities. Against a homogenous backdrop, they stand out, making them easy targets for discrimination or law enforcement (Schmalzbauer 2014). Without driver's licenses, they struggle to get around in small towns where public transit options are few (Bohon, Stamps, and Atiles 2008; Mendez and Nelson 2016; Schmalzbauer 2014). Without support for English language-learning, their children struggle in school (Dondero and Muller 2012). They have a high likelihood of moving to a place with a stronger co-ethnic community (Kritz, Gurak, and Lee 2011). Despite these challenges, immigrants living in new destinations express surprisingly high levels of satisfaction with their communities (Brazil 2019; Schmalzbauer 2014). 
This paper draws on interviews with Latin American men and women living in a nonmetropolitan county in Utah to understand the factors that lead immigrants to be satisfied (or dissatisfied) with their communities of residence, and the ways in which both sources of satisfaction and degree of satisfaction vary by gender. New destination communities in the 1980s and 1990s were often heavily male-dominated, with immigrant men coming to work but leaving wives and children behind elsewhere. Over time, these communities are becoming more "settled" and a growing number of immigrants live with their families (Harrison and Lloyd 2012; Marrow 2011; Smith and Winders 2008). However, this “settling” process is not occurring uniformly, with some new destinations (particularly in the Southeast and Midwest) remaining heavily male and others (particularly in the West) becoming gender-balanced or even female-dominated (Author et al. 2018; Castañeda and Sørensen 2019). Some new destinations, in other words, are both more able to attract and to keep immigrant women. Our interviews shed light on this process by demonstrating some of the ways in which immigrant men and women attach to communities.

The literature on immigrants in new destinations tends to focus on either assimilationdefined by Alba and Nee (2009) as the process by which ethnicity ceases to be a barrier to participation in mainstream institutions - or integration, which measures levels of social capital and participation in destination-society institutions and social networks (Goodman and Wright 2015; Hainmueller, Hangartner, and Pietrantuono 2017; Hall 2013; Wessendorf and Phillimore 2018). While the social processes of assimilation and integration are unquestionably important, they do not necessarily explain why immigrants come to, or stay in, a particular destination. Community attachment, on the other hand, is a strong predictor of future mobility (Bolan 1997). We draw, therefore, on both the immigrant integration and community attachment literatures to 
assess gender differences in both the causes and level of Latinx immigrants' attachment to their Utah community.

Community attachment theory has a long history in sociology, developing as a way to understand the effects of urbanization and industrialization on the social fabric (Kasarda and Janowitz 1974). Community attachment remains a somewhat nebulous concept that is operationalized in a variety of ways, but one common operationalization is a sense of rootedness in a community and a lack of interest in leaving (Cross 2003). Community attachment can also describe satisfaction with and a general sense of wellbeing in one's community (Goudy 1990; Sampson 1988). Attachment to a place develops, at least in part, through the stories that people tell each other about their community (Cross 2015). Our analysis focuses on the stories that our respondents tell about Northern Utah, both the stories that they heard before coming, that motivated them to come, and the stories that they tell to make sense of their lives as immigrants in a relatively homogenous community.

In the existing literature on immigrant integration, scholars have focused on differences in the integration process between new and traditional destinations, as well as on gendered experiences of integration, primarily in traditional destinations. Research treating integration in new destinations as a gendered process is still fairly limited, although sociologists and geographers have considered gendered integration processes in a handful of settings including southeastern Montana (Schmalzbauer 2014), Kentucky’s horse country (Snider 2017), Durham, North Carolina (Flippen and Parrado 2015), Williamsburg, Virginia (Deeb-Sossa and Mendez 2008), Ohio, and New Jersey (Dreby and Schmalzbauer 2013). We build on this literature in two ways. First, we examine the gendered experiences of immigrants in a destination with a different political, cultural, and economic context than the primarily Southern destinations in the existing 
literature, helping to identify the role that place characteristics play in immigrant experiences. Second, we incorporate ideas of place attachment and rootedness, in order to motivate research and theory-building on why a particular place might be more attractive to men or women.

\section{Literature Review}

Our analysis is situated between three related areas of literature: the new immigrant destinations literature, the literature on migration as a gendered process, and the literature on gender and community attachment. We provide a brief overview of each of these areas, then conclude with the benefits of synthesizing them.

\section{New Immigrant Destinations}

From 1971 to 1993 , nearly 80 percent of immigrants to the U.S. settled in just five states (Massey 1995). Since then, these top five destinations have seen a 60 percent drop in migration in favor of new destination sites (Massey 2008; Sánchez 2019). New destination sites include cities, towns and rural areas across the country (Donato et al. 2008; Kandel and Cromartie 2004; Singer 2004). This dramatic geographic diversification of immigration fueled a substantial body of research on the phenomenon of "new destinations" (Winders 2014). In contrast to traditional destinations, where local populations had a long history of exposure to newcomers and immigrant social networks were dense and well-established, new U.S. destinations had not seen high levels of immigration for at least 70 years (Singer 2004). Studies comparing the immigrant experience in new destinations to that in traditional destinations have produced a very mixed picture.

On one hand, immigrants are clearly drawn to new destinations because they perceive them to have advantages over traditional destinations. Advantages of new destinations include 
lower housing costs, safer neighborhoods, and less competition from other immigrants in the labor market (Light and Johnston 2009; Massey and Capoferro 2008; Schmalzbauer 2014). Marrow (2011) argues that the food processing industry in the South has allowed immigrants to achieve an upward economic mobility that would never be possible with the service jobs available in traditional urban gateways. Many immigrants in new destinations previously lived in traditional gateways, and often rate their lives in new destinations more positively than in traditional destinations (Brazil 2019; Marrow 2011; Schmalzbauer 2014).

On the other hand, numerous studies show the challenges of immigrant incorporation in new destinations. Lack of infrastructure in new destinations leaves immigrants without access to affordable housing or public transportation, leaving them spatially isolated (Atiles and Bohon 2003; Bohon et al. 2008; Mendez and Nelson 2016; Nelson and Hiemstra 2008; Schmalzbauer 2014). Undocumented status makes home ownership difficult, and immigrants have lower rates of home ownership in new destinations compared to traditional destinations (Drever 2008; Sánchez 2019). Latinx populations in new destinations are substantially less likely than their counterparts in traditional destinations to have health insurance (Monnat 2017). Lacking access to state supports, Latinx children are more likely to be born into poverty in new destinations, especially rural destinations, a finding which is not explained by parental characteristics (Lichter, Sanders, and Johnson 2015).

An additional challenge for new destination immigrants is the ethnic homogeneity and lack of pre-existing immigrant networks of new destinations. Latinx immigrants are "hypervisible" in new destinations, unable to blend in to existing, native Latinx communities and therefore susceptible to both everyday racism and state surveillance (Vaquera, Aranda, and Gonzales 2014). While many immigrants speak positively of their new destination homes, they 
also describe lives of intense isolation that involve going to work, coming home, and keeping out of sight as much as possible (Harrison and Lloyd 2012; Hiemstra 2010; Schmalzbauer 2014). Latina immigrants in Virginia felt that they lived in a "golden cage" (Deeb-Sossa and Mendez 2008). The increasing enforcement of immigration laws at the local level deepens immigrants' feelings of being constantly in danger (Hiemstra 2010; Winders 2007).

\section{Gendered Migration}

Context of settlement shapes the experience of immigrants, but gender is also an important factor in the immigrant experience (Donato, Enriquez, and Llewellyn 2017; Mahler and Pessar 2006; Pedraza 1991). The gender-segregated labor market means that immigrant women are less likely to hold jobs than their husbands, and when they do work, they are concentrated in caregiving and domestic service occupations (Altman and Pannell 2012; Moya 2007; Schmalzbauer 2014). Not working, or working in a private home, can protect women from the scrutiny of authorities, but can also be incredibly isolating (Hagan, Esbach, and Rodriguez 2008; Schmalzbauer 2014). Men's jobs put them at risk of surveillance, but protect them from being isolated from the larger society (Deeb-Sossa and Mendez 2008; Harrison and Lloyd 2012; Snider 2017).

Research dating back to the 1990s demonstrates that men's solo migration is often circular, while women's migration is associated with longer-term residence (Marrow 2011; Massey, Durand, and Malone 2002). Mexican women in particular express a stronger desire than men to settle permanently in the U.S. (Hondagneu-Sotelo 1994), and survey data show them to be more likely than Mexican men to self-identify as "American” (Jones-Correa et al. 2018). Learning to "do gender" in the ways accepted in the destination society is an important step in the process of achieving social acceptance (Karimi, Bucerius, and Thompson 2018; Korteweg 
2017). Women, with long-term settlement plans, may feel more eager to adopt destination norms than do men, who also find that acculturation can be in conflict with their sense of masculinity (Snider 2017).

\section{Gender and Community Attachment}

While studies analyzing the predictors of community attachment frequently include gender among their predictor variables, results are somewhat mixed. Depending on the measure of community attachment used, men express stronger attachment, women express stronger attachment, or there are no gender differences in attachment (Theodori 2004; Theodori and Luloff 2000). The most consistent conclusion is that men and women experience attachment in different ways, with women's attachment coming from their relationships with neighbors, churches, and schools, and men's coming from relationships at work and in community organizations (Beggs, Hurlbert, and Haines 1996). In a finding that mirrors the literature on gender and community attachment, Flippen and Parrado (2015) found that Latinx men and women in Durham, North Carolina reported very similar levels of overall perceived discrimination, but they experienced discrimination in different places and from different social actors. They also found that men were more likely to have long-term plans to stay in Durham, while women were more uncertain about their plans. A gender comparison of actual outmigration rates from Durham, however, found negligible differences between men and women (Parrado and Flippen 2016).

\section{Intersections of Destination and Gender}

Place context may shape gender differences in attachment. Brazil (2019) finds that overall, men are more satisfied with their neighborhoods, except in new destinations, where 
women are more satisfied, although none of the gender differences are large. The gender differences in integration can be substantial both between new and traditional destinations and across different new destinations. In traditional destinations, and even in some new destinations, immigrants have access to well developed social support networks and formal social services, creating more similarity between men's and women's experiences (Abrego and Schmalzbauer 2018; Dreby and Schmalzbauer 2013). In new destinations, structural conditions tend to isolate women to a greater degree than men (Deeb-Sossa and Mendez 2008; Schmalzbauer 2014; Snider 2017), but women's isolation is experienced very differently across new destinations. In Virginia, migrant women perceived their isolation negatively, as a sacrifice they had to make for economic gain (Deeb-Sossa and Mendez 2008), while migrant women in Montana saw it as an opportunity to practice an idealized intensive motherhood (Abrego and Schmalzbauer 2018; Schmalzbauer 2014). While these place-based differences are extremely important, none of the gender analyses of new immigrant destinations has explicitly considered community attachment and long-term residence plans. Given that new destinations do vary in their attractiveness to men versus women immigrants (Author et al. 2018), understanding gendered community attachment is an important contribution.

\section{Research Setting}

Case studies of Utah immigrant populations are relatively uncommon. In an analysis of Latinx immigration to the state as a whole, Solorzano (2005) argued that immigrants face challenges that are common to new destinations, such as conflicts with law enforcement and a high rate of high school dropouts among Latinx youth. Utah's religious homogeneity (over 60\% of the state's population is affiliated with the Church of Jesus Christ of Latter-Day Saints) adds 
an additional complication to immigrant integration. The Latinx community is divided between the approximately $30 \%$ who are members of the Church and receive greater social acceptance, and the majority who have different religious backgrounds and are more likely to feel like outsiders (Solorzano 2005).

Beyond its religious uniqueness, Utah is also characterized by unusual state-level immigration policy, which has swung back and forth between welcoming and exclusionary. Utah has allowed undocumented immigrants to obtain drivers licenses since 1999, and to attend college at in-state tuition rates since 2002, placing it as one of the more welcoming states for immigrants (Stewart and Jameson 2013). In 2008, however, the state passed one of the most restrictive immigration-related bills in the country, which allowed (and in some cases required) local law enforcement to enforce immigration law (Stewart and Jameson 2013). In 2011, another about-face resulted in the "Utah solution", a suite of inclusive legislation that prioritized keeping families together and even created a potential path for legalization of undocumented migrants (Petrzelka and Jacobs 2016). Many of the "Utah solution" laws were never implemented, and today Utah ranks around the middle of the road in terms of states that are welcoming to immigrants (Rodríguez, Young, and Wallace 2015).

While all of these contextual factors could have gendered consequences for immigration, the extent to which integration challenges in Utah are gendered has received limited attention. Smith and Mannon (2010) interviewed 32 immigrant Latina women enrolled in Englishlanguage courses in Northern Utah, and found that gender issues were not prominent in women's narratives of their own experiences. Instead, women were concerned about issues of social isolation, language difficulty, racial-ethnic prejudice, poverty, and lack of documentation. Without a sample of men, however, the extent to which male and female immigrants have 
similar concerns is unclear.

Our specific research site is a nonmetropolitan county in Northern Utah, which, like the state as a whole, has seen a dramatic expansion in Latinx immigration since 1990. Latinx residents went from less than $2 \%$ to over $10 \%$ of the county population between 1990 and 2015 . Nearly one third of the Latinx population of the county is foreign-born. Reflecting immigration patterns in the U.S. as a whole, immigrants from Latin America account for nearly 60 percent of all immigrants in the county, with the largest groups being Mexicans (39\%), Salvadorans (7.9\%), and Guatemalans (3.8\%). The foreign-born Latinx population in the county is just over $50 \%$ men, making the county typical of the sex-balanced new destinations of the Western U.S.

\section{Data and Methods}

To understand gendered integration in this context, we draw on 16 semi-structured interviews with immigrants from Latin American countries, conducted during the summer of 2018. Respondents were recruited using a purposive sampling strategy (Patton 2001). Initial contacts were made by posting flyers in local churches and community centers, and through posts in a Facebook group for the local Latinx community. Using a snowball sampling strategy, the interviewers requested that respondents pass on information about the study to members of their social networks. Respondents received a gift card as compensation for their time. In total, 7 men and 9 women participated in the interviews, with over half of the women recruited through the initial contacts strategy, but the majority of men coming through recommendations of earlier respondents.

The interviews utilized a standardized protocol that incorporated both closed- and openended questions. The protocol included a complete migration history, questions about the 
respondents' sources of information about the community before moving there, a variety of questions about the respondents' positive and negative perceptions about the community, and their intentions to remain in the future. The interviews lasted between 45 and 120 minutes. The protocol was developed in both English and Spanish, and the interview was conducted in the language of the respondent's choice. The majority of respondents (13) opted to interview in Spanish, and those interviews were conducted by the second author. The three English-language interviews were conducted by the first author. All interviews were audio recorded, transcribed, and translated into English where necessary. Any personally identifying information was deleted or altered in the transcripts by the authors, and each respondent was assigned a pseudonym. Because of concerns about our ability to protect confidentiality given our small sample in a small community, we did not directly ask about respondents' legal status. The research activities were approved by a university Institutional Review Board.

The first round of data analysis involved open coding the transcripts; while we were looking specifically for information relevant to community attachment, we also looked for other themes that emerged in the interviews. Themes that emerged at this stage of coding included the importance of tranquility, the ways in which respondents became more attached to the community over time, downplaying experiences of discrimination, and membership (or nonmembership) in the LDS Church. This descriptive coding process allowed all three authors to become familiar with the data (Richards and Morse 2012). In a second round, we developed indepth sub-codes to identify specific experiences, beliefs, or ideas. The first two authors both coded the entire dataset, achieving an average Kappa coefficient of .7 across all codes. Where there were discrepancies between our coding, we discussed and in some cases expanded the codes to reach agreement. All coding was done using NVivo 12 software. 


\section{Results}

Table 1 presents the assigned pseudonyms and demographic information on the 16 respondents. Over half of the respondents were born in Mexico, representing the overall composition of the Latinx population in the community, but the remainder came from other countries in both Central and South America. The youngest respondent was 25, while the oldest was 60 , with the average age of both men and women being in the 40s. Most respondents had been in the U.S. for many years, often more than 20. Thirteen of the respondents had lived somewhere else in the U.S. (generally outside of Utah) before coming to the study community, so times in the study community are generally shorter than times in the U.S. Still, while three respondents were relatively recent arrives to the study community, most of the respondents had lived there for more than 10 years.

\section{<<TABLE 1 ABOUT HERE >>}

All but two of the respondents were employed in some manner. The two not currently employed were both women who identified as homemakers/mothers, and both had been employed in the community in the past, one in a professional and one in a service occupation. Although the interviewers did not formally collect information on the socioeconomic status of respondents, they represent a range of educational levels and occupational types. Several of the respondents had higher education, and even graduate degrees. The women respondents were overall more educated than the men, with only one man (Andres) having a college degree and a professional job. The most common jobs for both male and female respondents were in the service industry, although two men reported working in agriculture and two respondents were small business owners. 
Legal status is not shown in the table for confidentiality reasons. Many, but not all, of the respondents were living and working legally in the U.S. at the time of the interview. However, even among those who were documented, some had originally entered the U.S. without documents, and some were members of mixed status families (eg, the respondent was documented but their partner was not). There was an association between legal status and LDS membership. About half of the sample were LDS Church members, and most of them were documented, possibly because of their stronger social ties to the native community (two LDS respondents, for example, were married to native-born U.S. citizens). In the remainder of this section, we discuss four major themes that emerged from the interview: the process of developing attachment to Northern Utah; the importance of tranquilidad (tranquility) in respondents' satisfaction with their community; experiences of discrimination; and gender differences in plans for long-term residence.

\section{An Accidental Destination: Developing Attachments to Northern Utah}

None of our respondents had any prior knowledge of this Northern Utah community before their relatives or friends encouraged them to visit or move. Their decision to relocate to the community stemmed from the descriptions of these relatives and friends. Participants were driven by two primary reasons to relocate. The first one was knowing someone that could help with jobs and housing or provide other assistance, ${ }^{1}$ which was mentioned by 11 respondents. The second reason was to reunite with family members. Two men had come primarily to be with their grandchildren and two women had come to reunite with their parents. Only one of the male

\footnotetext{
${ }^{1}$ It is important to note that the concept of "help" (ayuda) was defined differently by gender - while men referred to "help" exclusively in terms of jobs and housing for themselves, women conceptualized "help" even further and in more abstract terms. "Help" included relatives or friends providing them with information, rides, company, family responsibilities, and health care as well as jobs. Women did not distinguish whether these jobs were for themselves, their partners, or both.
} 
participants chose the community because he visited and fell in love with the scenery. This finding suggests that migrants chose this community based on their social connections rather than the intrinsic qualities of the place. Learning about this community is accidental in the sense that if it was not for their social networks these immigrants will have not known about it and therefore not considered it.

Although most respondents heard glowing accounts of the community from the person who was trying to convince them to move, many did not like it at first. Leyla experienced the kind of isolation that many women in new destinations face: "I didn't know how to drive, so I was like trapped in [town], because we don't have bus, we don't have store, we don't have gas station, we don't have anything." Hernando felt lost without the network of friends and services he had relied on in California: "When I got here I started to see, because in California I earned well, I had all the services. I fought with my wife, I said 'Where did you send me? Look I do not know anything!"” And Sandra simply hated her first experience with a rural area. She reported that she told the sister who encouraged her to move: "What is this? There is nothing here. It smells like cow...this place is horrible...You will never be able to convince me [to stay]." Although half of the respondents described challenges of settling in a rural new destination and negative feelings that emerged through the experience, the participants also described that finding a job made a difference in their perception of the place. The concept of "stability" was also very important in respondents' increasing attachment to the community. They defined stability as composed of job security, social connections, and everyday knowledge while in a beautiful, calm, and secure place for them, but more importantly for their children. Attachment to the community occurred once the participants felt that they had reached "stability." Sandra, for example, intended on only a short stay in Northern Utah; she needed her 
sister's care during a difficult pregnancy. "When we came here, for some reason all the pieces started fitting together and [my husband] found a job and I found a job. Going back to where we came from wasn't even an option anymore. We made our life here, my son was born and that was it." Referencing her earlier assertion that her sister would "never" convince her to stay in such a small town, Sandra laughingly said "The fish dies through its mouth. So I am here and I love it!" Luisa also suggested that stability was an important aspect in her growing attachment to the community:

I am very into family, my partner. If my partner has a good job and the people are not bothering you, and you are calm (tranquilo) in one place, you don't have the necessity to move. Thanks to God we are stable, we have our daughters, we have been in this apartment for a few years. For me this town is very good because my husband has a good job.

\section{In Search of "La Vida Tranquila": Narratives of Community Satisfaction}

Despite the difficulties that adjusting to life in a rural new destination presented, nearly all the respondents (both men and women) ended up with a deep fondness for the community specifically because of its rurality. That fondness was expressed in three themes that showed up in nearly every interview. First, respondents were attached to the natural landscape. Carolina expressed a common sentiment when she said: "The place in itself is physically beautiful, the mountains, the cute trees, when it snows it looks incredible, when the flowers come out too." While most respondents appreciated the landscape aesthetically, several were also attached to the inexpensive recreational activities it afforded, whether hiking, picnics, taking kids to the park, or simply going for a walk or a run. Indeed, the opportunity for children to spend time outside was a significant part of the community's appeal. Pedro, who was unhappy with his work life in Northern Utah, did not want to leave because of his child: "The kid can be playing outside. Since the houses are apart there are more spaces for the baby to be entertained....For me [this] is the 
place that I like the most for raising my son.”

Second, the low cost of living in a small community was appealing to our respondents, particularly to those who had previously lived in larger cities in California or elsewhere in the U.S. In particular, they valued the higher standard of living that lower costs (especially lower housing costs) allowed them to achieve. Leyla, for example, was extremely proud of the house that she and her ex-husband had built in one of the county's smaller towns. Leyla's house was not large, but it was modern, carefully decorated, and had a yard, and she could not imagine being able to afford anything similar if her family had remained in their previous residence in Florida. Rodolfo had a similar story. He had always wanted to buy a house and stop "wasting" money on rent, but houses in California were out of reach. In Utah, however, he was able to achieve his dream of home ownership. Even those not able to buy homes (in some cases because of legal status) still felt that low costs allowed them a higher standard of living.

Finally, and most importantly, a significant majority of the respondents described the community by referring to the northern Utah town as a tranquil place - un lugar tranquilo. Although most commonly translated into English as quiet or tranquility, our respondents used tranquilidad to describe a general sense of comfort and wellbeing, and was especially used to describe a sense of safety. Sandra stated: "I can go to sleep tranquila knowing that nothing is going to happen to me nor my kids. I can go out with my children to walk and everything will be okay." Similarly, when Pedro was asked to elaborate on his comment that the community was a tranquil place, he stated:

As I said, I can have my door open. Sometimes I have forgotten the keys outside and then they are still there. I live in a house where I have my own space. I can go out and be outside. I mainly think about that, when I am in the house, I don't have to worry about "Is the door open?"; "Is the car still open?"

The comparison between Northern Utah and previous places of residence heightened the value of 
Northern Utah's tranquility. Camilo, who had left Mexico initially for Los Angeles, felt that Los Angeles could hardly be considered an improvement: "Almost the same as in my country, wherever you go, you see gangs, violence... It was not a very suitable place for [my daughter] to grow up." For Camilo and other respondents, Northern Utah was closer to the idealized version of the U.S. that they had once imagined, and a chance at the vida tranquila that they longed for.

Being a member of the LDS Church influenced the ways in which respondents expressed their attachment to the community. Hernando, for example, felt that Northern Utah was an ideal place to raise children because of the example set by members of the Church. Carolina expressed satisfaction at the opportunity to live in an area where so many people shared her faith. But we found no evidence that Church members were more satisfied with the community overall, and the themes of tranquility, safety, beauty, and low cost of living were relevant across all religious faiths. The same was true for legal status. While several of the documented respondents expressed concern over how difficult life was for their undocumented friends and neighbors, current and formerly undocumented respondents were no less positive about Northern Utah. While several did have very negative experiences in the past related to their undocumented status, all had happened in other parts of the country.

\section{Discrimination and Community Attachment}

While overall assessments of life in Northern Utah were positive, most of our respondents still had some negative feelings about the community. A lack of well-paid or prestigious job opportunities, a lack of stores, bars or other things to do in a small town, and the cold winters were frequently mentioned as negative aspects. But the single most common negative aspect of the community mentioned was discrimination or racism. Of the 16 respondents, 8 reported personal experiences of discrimination, either as immigrants or people of 
color (or in one case, as a non-Mormon). Many of the discriminatory instances mentioned were relatively mild, but persistent. For example, Anabel explained that both she and her white, Utahborn husband spoke to their children in Spanish, but that they were treated very differently when they did so in public.

So if I'm at Walmart, and I'm speaking Spanish to my kids, I so often get the comment: "It's America_English." Or, "It's disrespectful, speak English to your kids." Or, "It's rude."...I get those comments so often it is now a part of my life, I just ignore them. But my husband, if he's speaking Spanish to them in Walmart, he gets, "Oh, your kids are so lucky, you're teaching them Spanish, wow, they are going to be bilingual, that's awesome!"

Camilo shared a similar story about being criticized for speaking Spanish in public. Others reported more serious discrimination. Andres and Maritza, who both spoke English well, felt that their accents led employers to view them as less capable and had struggled to find employment in their desired field.

Of the 8 respondents who reported discrimination, 3 did so only after probing, and were quick to point out that the discrimination had no effect on their daily lives. Camilo was dismissive of the people who criticized him for speaking Spanish: "There are always going to be ridiculous people. But as I said, for me, it doesn't interest me nor affects me.” The idea that racism was unavoidable, but that one could choose to let it affect them or not, was shared by Mario and Natalia as well. Of the 5 respondents who both reported discrimination and did not choose to downplay it (Andres, Anabel, Carolina, Maritza, and Sandra) it is important to note that only one was a man. Men were both less likely to report discrimination even with probing, and more likely to downplay it when they did. While men were less subject to, or less sensitive to, discrimination, being a member of the LDS Church did not protect immigrants from experiences of discrimination. In fact, of the five respondents who were most harshly critical of racism, four were Church members. Possibly, the increased opportunities to interact with local 
whites that come with LDS practice actually increased immigrants' exposure to discrimination.

Experiences of discrimination did not seem to have much effect on overall levels of community satisfaction. Sandra and Maritza, for example, were the harshest critics of local racism. When asked if there was anything she didn't like about the community, Sandra replied, without hesitation:

There are many racist people. There are many people that... this can sound bad. There are many uneducated people, people that have their minds closed, people that don't go out. There are many students and they are ok. But with the people that are native to here, it is people that are very closed minded, they don't travel, they see you as someone that is invading their territory.

But when she was asked for an overall assessment of the community, her reply was: "It is truly beautiful. I tell people that it is really ugly so that they don't come [laughs], so that it doesn't get crowded...But it is truly a beautiful place, it is gorgeous, I love that the traffic is not traffic, we don't have a freeway, wherever I want to go I can get there in minutes.” Maritza's overall assessment of Northern Utah was equally positive, and no less positive than those who reported no discrimination.

One reason that experiencing discrimination did not seem to decrease community satisfaction was that respondents felt that they would be subject to discrimination anywhere in the U.S. Some respondents had personal experience of much worse situations. Anabel, for example, was visibly irritated when she described being harassed at Walmart for speaking Spanish. But when she later described a much older incident where she was humiliated by a teacher in Texas, she was nearly in tears and had to break off the interview for a few minutes. Andres, on the other hand, had never lived anywhere else in the U.S., but he knew many people who had, and he was an avid consumer of news. He had no illusions that a dark-skinned Spanishspeaker could live anywhere in the U.S. without facing hostility. 


\section{Gender Differences in Long-term Residence Plans}

A desire to continue residing in a community for the long-term is an important aspect of the community attachment literature, and important for understanding how and whether new destinations retain immigrant residents. This is the area of our research in which gender differences appeared most dramatically. As Table 2 shows, four of the 16 thought it unlikely that they would still be living in Northern Utah in 10 years time, and all four were women. Another three women and four men felt that they would almost certainly remain in Northern Utah in the long term, with another two women and three men uncertain about their long-term plans. In the cases of uncertainty, the respondents felt torn between their attachment to Northern Utah and the feeling that they or their family members would have better employment opportunities elsewhere. Although women were happy with this community, in our sample, they were much less likely than men to express an intention to stay here. Women were not just more uncertain about their futures, several of them had specific plans to leave. None of the men in our sample thought it most likely that they would leave, although a few considered it possible.

Why do women not intend to stay? Table 2 shows a potential association between women's greater experiences of discrimination and their lesser attachment to Northern Utah. Of the four women who gave the strongest narratives of discrimination (Anabel, Carolina, Maritza, and Sandra), none definitely planned to stay. This association did not appear among the men. Andres, the only man who told a story of discrimination without downplaying it, was also one of the most committed to staying in the community: "My wife insisted on moving. But I said no. No, I like the place." Of the three men who were uncertain about staying, two listed limited employment or business opportunities as the most negative aspects of the community, and directly attributed their uncertain future plans to these limited employment opportunities. 
Nevertheless, we are hesitant to conclude that women are less attached to the community because they are more exposed and attuned to discrimination. None of the women who experienced discrimination listed that discrimination as a reason that they might want to leave. Most of them, in fact, highlighted that they would leave only reluctantly, generally for family reasons. Anabel's husband wanted to switch careers, and had not found any opportunities in the new career locally, so was looking in bigger cities. Sandra's husband currently had satisfying work locally, but she was not convinced that his employment was stable, and if he needed new employment she thought they might leave. She jokingly "touched wood" during the interview to demonstrate her hope that her family would not have to leave. Carolina, in her late 30s and single, thought that her romantic prospects would be better in her home country.

Indeed, several women thought that it was likely or possible that family reasons would draw them away from Northern Utah, even though they were very happy there. Leyla, for example, could only come up with the winter snows when asked to list negative things about her community. She ran a fairly successful small business and owned a house that she loves. Leyla's teenage daughter, on the other hand, disliked the conservative culture of Northern Utah, and was vocal about her desire to live elsewhere once she finished high school. Leyla expected that once her daughter left, she would follow within a few years, as she could not imagine being separated from her. Women's lesser attachment to the community in this sample seemed to reflect their greater dependence on the decisions of husbands and children, more than gender differences in the experience of discrimination. Men like Andres felt more able to articulate plans based on just their own desires.

\section{Discussion and Conclusion}


In some respects, gender differences in the perceptions of desirable and undesirable aspects of a community were smaller than we expected. Both men and women expressed very high levels of satisfaction with Northern Utah, and the reasons that they were satisfied were similar across our entire sample. Not only did gender have no effect on community satisfaction, but other factors such as LDS Church membership and legal status also had limited effect. Many respondents had experienced some level of racism in the community, and women seemed particularly prone to it and sensitive to its effects, but neither men nor women saw it as a reason to leave the community. The most striking gender difference was in long-term plans; women expressed much less certainty that they would remain in Northern Utah over the long term. This difference in community attachment seemed to be related to women's greater dependence on the decisions of other family members, and not due to any gender differences in community satisfaction.

These findings raise a number of questions. First, why were respondents so universally satisfied with the community? In part, this may simply be selection effects; people who are not interested in the tranquility of a small community and have a strong preference for urban amenities may not come to Northern Utah in the first place, and those who are not happy there may simply leave. Nevertheless, the immigrants studied by Schmalzbauer (2014) and by DeebSossa and Mendez (2008) would have been similarly selected, and both of those studies found significant gender differences in community integration, with women experiencing social isolation and - in Virginia—feeling "trapped". One factor may be state policy; Utah has allowed undocumented immigrants to obtain drivers' licenses for more than 10 years, in contrast to both Montana and Virginia. All but one of our respondents had both a license and access to a car, which also made it possible for them to be employed and prevented the type of socio-spatial 
isolation described in many new destination studies (Deeb-Sossa and Mendez 2008; Hiemstra 2010; Mendez and Nelson 2016; Schmalzbauer 2014). Another potential explanation is the LDS majority in the community. Because a substantial number of Latinx residents in this community are LDS, local white Church members have substantial opportunities to get to know their Latinx neighbors. The social bonds formed through religion may have spillover effects that lead to friendlier relationships even with Latinx immigrants who are not Church members.

Second, why did women experience (or at least report) more perceived discrimination? This is contrary to the literature on perceived discrimination among Black Americans, where men consistently report more discrimination (Ifatunji and Harnois 2015). This also contradicts the findings of Flippen and Parrado (2015) in North Carolina, where men and women reported similar frequency of discrimination, although from different sources. The women in our sample reported more opportunities for interaction with locals than men did, in part because more of the women were members of the LDS Church, but also because women went shopping, registered children for school and attended school events, and visited places like the bank. Although such activities are generally positive signs of integration into a community, they also opened women up to discriminatory comments and actions.

This research had a number of limitations. The sample comes from a small pilot study, with only 16 respondents. In some areas, such as the perception of tranquility and the tendency to downplay experiences of discrimination, 16 interviews did reach saturation. In other areas, it may not have. For example, the possible link between experiences of discrimination and attachment to the community may have become clear in larger sample. Another limitation of the sample is that a majority of the respondents had been living in the community for more than 10 years. This almost certainly biased the sample towards those immigrants who were most attached 
to the community, as those who struggled to integrate or did not like the area are more likely to have left after a short residence. Our findings, therefore, can only be interpreted as relevant to long-term Latinx residents. Despite these limitations, our findings raise two important issues about gender and community attachment in new destinations.

First, gender differences in perceptions of what makes a destination desirable or undesirable are not a promising avenue for explaining why some new destinations are more attractive to women immigrants from Latin America. Instead, Northern Utah appears to be particularly attractive to Latina women because both men and women perceive it as a desirable place to settle down and raise a family. While our respondents compared Northern Utah favorably to traditional destinations in California, Texas, and Florida, none had lived in any of the new destinations of the Southeast. Future research could consider why Southeastern new destinations have been slower to attract women and families, and the extent to which factors such as perceived tranquility and attachment to the natural environment influence that process.

Second, our findings are notable for the very high levels of community attachment that our respondents present. While high levels of immigrant community satisfaction and integration, particularly in new destinations and particularly in the West, are not uncommon in the literature (Brazil 2019; Nelson and Hiemstra 2008; Schmalzbauer 2014; Smith and Winders 2008), our respondents were extremely positive about Northern Utah. This positive picture is all the more notable given the timing of the interviews (summer 2018), when anti-immigrant rhetoric and government policies were more prominent in the U.S. than it had been in the pre-Trump era when most existing research was conducted (Lopez, Gonzalez-Barrera, and Krogstad 2018). Respondents were well aware of this negative political climate, and in many cases fearful for their own or their friends' and family members' futures in this country. Yet their fears, and their 
anger at the national political climate, did not seem to affect their attachment to the local community. Politically, this could have important implications for local communities dealing with growing immigrant populations. Attachment, it seems, can be fostered at a local level, even in an unfavorable political climate.

Future research should consider the factors that promote community attachment for immigrants at the local level. In our sample, respondents had multiple opportunities for both employment and interaction with locals. Although those interactions were not always positive, they seem to protect immigrants, particularly women, from social isolation. In the absence of more comparative research, we can only speculate as to why this community generated more integration and attachment than others did. Possible candidates for future research include the role of state and local policies (particularly access to drivers' licenses), the role of common cultural or social institutions such as churches, women's employment opportunities, and the accessibility of outdoor amenities such as walkable neighborhoods, parks, and playgrounds.

\section{References}

Abrego, Leisy J. and Leah Schmalzbauer. 2018. "Illegality, Motherhood, and Place: Undocumented Latinas Making Meaning and Negotiating Daily Life.” Women's Studies International Forum 67:10-17.

Alba, Richard D. and Victor Nee. 2009. Remaking the American Mainstream: Assimilation and Contemporary Immigration. Harvard University Press.

Altman, Meryl and Pannell. 2012. "Policy Gaps and Theory Gaps: Women and Migrant Domestic Labor.” Feminist Economics 18(2):291-315.

Atiles, Jorge H. and Stephanie A. Bohon. 2003. "Camas Calientes: Housing Adjustments and 
Barriers to Social and Economic Adaptation among Georgia’s Rural Latinos." Southern Rural Sociology 19(1):97-122.

Author et al. 2018. "No Title."

Beggs, John J., Jeanne S. Hurlbert, and Valerie A. Haines. 1996. “Community Attachment in a Rural Setting: A Refinement and Empirical Test of the Systemic Model 1." Rural Sociology 61(3):407-26.

Bohon, Stephanie A., Katherine Stamps, and Jorge H. Atiles. 2008. "Transportation and Migrant Adjustment in Georgia." Population Research and Policy Review 27(3):273.

Bolan, Marc. 1997. "The Mobility Experience and Neighborhood Attachment.” Demography $34(2): 225-37$.

Brazil, Noli. 2019. "Hispanic Neighbourhood Satisfaction in New and Established Metropolitan Destinations." Urban Studies 0042098018809913.

Castañeda, Adriana Hernández and Todd A. Sørensen. 2019. “Changing Sex-Ratios Among Immigrant Communities in the USA.” Journal of Economics, Race, and Policy 2(1):20-42.

Cross, Jennifer. 2003. "Conceptualizing Community Attachment."

Cross, Jennifer Eileen. 2015. "Processes of Place Attachment: An Interactional Framework." Symbolic Interaction 38(4):493-520.

Deeb-Sossa, Natalia and Jennifer Bickham Mendez. 2008. "Enforcing Borders in the Nuevo South: Gender and Migration in Williamsburg, Virginia, and the Research Triangle, North Carolina." Gender \& Society 22(5):613-38.

Donato, Katharine M., Laura E. Enriquez, and Cheryl Llewellyn. 2017. "Frozen and Stalled? Gender and Migration Scholarship in the 21st Century.” American Behavioral Scientist 61(10):1079-85. 
Donato, Katharine M., Charles Tolbert, Alfred Nucci, and Yukio Kawano. 2008. "Changing Faces, Changing Places: The Emergence of New Nonmetropolitan Immigrant Gateways.” Pp. 75-98 in New Faces in New Places: The Chaning Geography of American Immigration, edited by D. S. Massey. New York: Russell Sage Foundation.

Dondero, Molly and Chandra Muller. 2012. "School Stratification in New and Established Latino Destinations.” Social Forces 91(2):477-502.

Dreby, Joanna and Leah Schmalzbauer. 2013. "The Relational Contexts of Migration: Mexican Women in New Destination Sites.” Sociological Forum 28(1):1-26.

Drever, Anita I. 2008. "New Orleans: A Re-Emerging Latino Destination City.” Journal of Cultural Geography 25(3):287-303.

Flippen, Chenoa A. and Emilio A. Parrado. 2015. "Perceived Discrimination among Latino Immigrants in New Destinations: The Case of Durham, North Carolina." Sociological Perspectives 58(4):666-85.

Goodman, Sara Wallace and Matthew Wright. 2015. "Does Mandatory Integration Matter? Effects of Civic Requirements on Immigrant Socio-Economic and Political Outcomes.” Journal of Ethnic and Migration Studies 41(12):1885-1908.

Goudy, Willis J. 1990. “Community Attachment in a Rural Region 1.” Rural Sociology 55(2):178-98.

Hagan, Jacqueline, Karl Esbach, and Nestor Rodriguez. 2008. “U.S. Deportation Policy, Family Separation, and Circular Migration.” International Migration Review 42(1):64-88.

Hainmueller, Jens, Dominik Hangartner, and Giuseppe Pietrantuono. 2017. "Catalyst or Crown: Does Naturalization Promote the Long-Term Social Integration of Immigrants?" American Political Science Review 111(2):256-76. 
Hall, Matthew. 2013. "Residential Integration on the New Frontier: Immigrant Segregation in Established and New Destinations.” Demography 50:1873-96.

Harrison, Jill Lindsey and Sarah E. Lloyd. 2012. "Illegality at Work: Deportability and the Productive New Era of Immigration Enforcement.” Antipode 44(2):365-85.

Hiemstra, Nancy. 2010. 'Immigrant 'Illegality' as Neoliberal Governmentality in Leadville, Colorado." Antipode 42(1):74-102.

Hondagneu-Sotelo, Pierrette. 1994. Gendered Transitions: Mexican Experiences of Immigration. Berkeley, CA: University of California Press.

Ifatunji, Mosi Adesina and Catherine E. Harnois. 2015. "An Explanation for the Gender Gap in Perceptions of Discrimination among African Americans: Considering the Role of Gender Bias in Measurement." Sociology of Race and Ethnicity 2(3):263-88.

Jones-Correa, Michael, Helen B. Marrow, Dina G. Okamoto, and Linda R. Tropp. 2018.

"Immigrant Perceptions of U.S.-Born Receptivity and the Shaping of American Identity." RSF: The Russell Sage Foundation Journal of the Social Sciences 4(5):47-80.

Kandel, William and John Cromartie. 2004. New Patterns of Hispanic Settlement in Rural America. Washington, DC: U.S. Department of Agriculture, Economic Research Service.

Karimi, Ahmad, Sandra M. Bucerius, and Sara Thompson. 2018. "Gender Identity and Integration: Second-Generation Somali Immigrants Navigating Gender in Canada.” Ethnic and Racial Studies 1-20.

Kasarda, John D. and Morris Janowitz. 1974. "Community Attachment in Mass Society." American Sociological Review 328-39.

Korteweg, Anna C. 2017. “The Failures of 'Immigrant Integration': The Gendered Racialized Production of Non-Belonging." Migration Studies 5(3):428-44. 
Kritz, Mary M., Douglas T. Gurak, and Min-Ah Lee. 2011. "Will They Stay? Foreign-Born OutMigration from New US Destinations.” Population Research and Policy Review 30(4):53767.

Lichter, Daniel T., Scott R. Sanders, and Kenneth M. Johnson. 2015. "Hispanics at the Starting Line: Poverty among Newborn Infants in Established Gateways and New Destinations.” Social Forces 94(1):209-35.

Light, I. and M. F. Johnston. 2009. "The Metropolitan Dispersion of Mexican Immigrants in the United States, 1980 to 2000.” Journal of Ethnic and Migration Studies 35(1):3-18.

Lopez, Mark Hugo, Ana Gonzalez-Barrera, and Jens Manuel Krogstad. 2018. More Latinos Have Serious Concerns About Their Place in America Under Trump. Washington, D.C.

Mahler, Sarah J. and Patricia R. Pessar. 2006. “Gender Matters: Ethnographers Bring Gender from the Periphery toward the Core of Migration Studies.” International Migration Review 40(1):27-63.

Marrow, Helen. 2011. New Destination Dreaming: Immigration, Race, and Legal Status in the Rural American South. Stanford University Press.

Massey, Douglas, Jorge Durand, and Nolan J. Malone. 2002. Beyond Smoke \& Mirrors: Mexican Immigration in an Era of Economic Integration. New York: Russell Sage Foundation.

Massey, Douglas S. 1995. "The New Immigration and Ethnicity in the United States." Population and Development Review 631-52.

Massey, Douglas S. 2008. "New Faces in New Places: The Changing Geography of American Immigration."

Massey, Douglas S. and Chiara Capoferro. 2008. "The Geographic Diversification of American Immigration.” Pp. 25-50 in New Faces in New Places: The Changing Geography of 
American Immigration. New York, NY: Russell Sage Foundation.

Mendez, Jennifer Bickham and Lise Nelson. 2016. "Producing 'Quality of Life' in the 'Nuevo South': The Spatial Dynamics of Latinos' Social Reproduction in Southern Amenity Destinations." City \& Society 28(2):129-51.

Monnat, Shannon M. 2017. “The New Destination Disadvantage: Disparities in Hispanic Health Insurance Coverage Rates in Metropolitan and Nonmetropolitan New and Established Destinations.” Rural Sociology 82(1):3-43.

Moya, Jose C. 2007. "Domestic Service in a Global Perspective: Gender, Migration, and Ethnic Niches." Journal of Ethnic \& Migration Studies 33(4):559-79.

Nelson, Lise and Nancy Hiemstra. 2008. "Latino Immigrants and the Renegotiation of Place and Belonging in Small Town America." Social \& Cultural Geography 9(3):319-42.

Parrado, Emilio A. and Chenoa A. Flippen. 2016. “The Departed: Deportations and OutMigration among Latino Immigrants in North Carolina after the Great Recession.” The ANNALS of the American Academy of Political and Social Science 666(1):131-47.

Patton, Michael Quinn. 2001. Qualitative Research and Evaluation Methods. Third. Thousand Oaks, CA: SAGE Publications.

Pedraza, Silvia. 1991. "Women and Migration: The Social Consequences of Gender." Annual Review of Sociology 17(1):303-25.

Petrzelka, Peggy and Paul Jacobs. 2016. "Why Utah? The 'Reddest of Red States' and Inclusive Immigration Reform.” The Social Science Journal 53(2):156-66.

Richards, Lyn and Janice M. Morse. 2012. Readme First for a User's Guide to Qualitative Methods. Sage.

Rodríguez, Michael A., Maria-Elena Young, and Steven P. Wallace. 2015. Creating Conditions 
to Support Healthy People: State Policies That Affect the Health of Undocumented

Immigrants and Their Families. University of California, Global Health Institute.

Sampson, Robert J. 1988. "Local Friendship Ties and Community Attachment in Mass Society:

A Multilevel Systemic Model.” American Sociological Review 53(5):766-79.

Sánchez, Luis A. 2019. "Homeownership Among Latin American Immigrants in New

Destinations.” Sociological Inquiry 89(1):11-45.

Schmalzbauer, Leah. 2014. The Last Best Place?: Gender, Family, and Migration in the New

West. Stanford University Press.

Singer, Audrey. 2004. The Rise of New Immigrant Gateways. Washington, DC: Brookings

Institution.

Smith, Barbara Ellen and Jamie Winders. 2008. “'We'Re Here to Stay’: Economic

Restructuring, Latino Migration and Place-Making in the US South." Transactions of the Institute of British Geographers 33(1):60-72.

Smith, Rebecca A. and Susan E. Mannon. 2010. "NNibbling on the Margins of Patriarchy': Latina Immigrants in Northern Utah.” Ethnic and Racial Studies 33(6):986-1005.

Snider, Mitchell. 2017. "Being a Man in the Horse Capital: Mexican Farmworkers' Masculinities in Kentucky." Gender, Place \& Culture 24(3):343-61.

Solorzano, Armando. 2005. "At the Gates of the Kingdom: Latino Immigrants in Utah, 1900 to 2003." Pp. 177-212 in Beyond the Gateway: Immigrants in a Changing America, edited by E. M. Gozdziak and S. F. Martin. Lanham: Lexington Books.

Stewart, Julie and Kenneth P. Jameson. 2013. "Interests Aren’t Everything: An Exploration of Economic Explanations of Immigration Policy in a New Destination.” International Migration 51(4):33-53. 
Theodori, Gene L. 2004. "Exploring the Association between Length of Residence and Community Attachment: A Research Note.” Southern Rural Sociology 20(1):107-22.

Theodori, Gene L. and Albert E. Luloff. 2000. "Urbanization and Community Attachment in Rural Areas.” Society \& Natural Resources 13(5):399-420.

Vaquera, Elizabeth, Elizabeth Aranda, and Roberto G. Gonzales. 2014. "Patterns of Incorporation of Latinos in Old and New Destinations: From Invisible to Hypervisible." American Behavioral Scientist 58(14):1823-33.

Wessendorf, Susanne and Jenny Phillimore. 2018. 'New Migrants' Social Integration, Embedding and Emplacement in Superdiverse Contexts." Sociology 53(1):123-38. Winders, Jamie. 2007. "Bringing Back the (B)Order: Post-9/11 Politics of Immigration, Borders, and Belonging in the Contemporary US South.” Antipode 39(5):920-42.

Winders, Jamie. 2014. “New Immigrant Destinations in Global Context.” International Migration Review 48(S1):S149-79. 